\title{
Autofrettage of component-like ultra high Strength Steel Specimens with intersecting Holes
}

\author{
Carl Fällgren ${ }^{1 *}$, Thomas Beier ${ }^{1}$, Michael Vormwald ${ }^{1}$ and Andreas Kleemann ${ }^{2}$ \\ ${ }^{1}$ Technical University of Darmstadt, Department of Civil and Environmental Sciences, Materials \\ Mechanics Group, Franziska-Braun-Str. 3, 64287 Darmstadt, Germany \\ ${ }^{2}$ Institute of Materials Research and Testing Weimar at the Bauhaus-University (MFPA), \\ Coudraystraße 9, 99423 Weimar, Germany
}

\begin{abstract}
This work is primarily concerned with the fatigue life of highpressure-bearing components with intersecting holes, typically used in Diesel engine fuel injection systems. The investigation focuses on specimens with intersecting holes that have undergone the process of Autofrettage (single mechanical overload), which is typically used to extend the fatigue life of components loaded by cyclic internal pressure. The resulting residual stress distribution thus influences the fatigue failure and especially the crack propagation behaviour of the components. In previous works, results showed that besides crack initiation, crack arrest behaviour has to be taken into account when calculating fatigue lives of autofrettaged specimens as the endurance limit is otherwise underestimated. In order to achieve reliable results, material testing with samples made of the ultra high strength steel W360 was performed. The resulting test data were used to simulate the Autofrettage process with finite-element analysis. Calculated residual stress distributions were used to determine at which levels of subsequent cyclic loading crack initiation would occur. For predicted crack initiation, the simulated residual stress distribution was used to investigate the crack propagation behaviour with fracture mechanics based approaches of different complexity in order to identify possible crack arrest or crack propagation. Calculated results were compared to experimental test data from component-like specimens. The comparison showed that the fracture mechanics based approaches are capable of describing the crack arrest and propagation behaviour reliably.
\end{abstract}

\section{Introduction}

As highly pressurised combustion engines, as Diesel engines, have to become more efficient in order to achieve the ecological goal of minimising emissions from those types of applications, the operating pressures have to be increased. For this reason new steel grades with higher fatigue strengths and endurance limits have to be introduced. For currently used steel grades, e.g. $42 \mathrm{CrMo} 4$, endurance limits can be increased by a factor greater than 2 , if

* Corresponding author: faellgren@wm.tu-darmstadt.de 
inner-pressure-bearing components and specimens are subjected to Autofrettage before they are used in their designated environments, see $[1,2,3,4,5]$. The process of Autofrettage, which is a single peak overload, introduces life-prolonging, beneficial residual stresses in highly-stressed areas, e.g. notches, of the components $[5,6]$. As the usage of ultra high strength steels for these applications has not yet been investigated, this report focuses on the evaluation of the potential using the example steel W360.

\subsection{Material Characterization}

The material used was a stainless electro-slag remolten X50CrMoV5-3-1 ultra high strength steel. The material's brand name "W360" (brand name of Böhler Edelstahl GmbH \& Co. KG) will be used in this paper. Material testing was performed at the Material Mechanics Group laboratory in Darmstadt with hourglass specimens with the smallest diameter of $5 \mathrm{~mm}$. Three of the manufactured specimens were used for quasi-static tensile testing. The data obtained is shown in Table 1.

Table 1. Averaged characteristic values from tensile testing with W360 hourglass specimens.

\begin{tabular}{|c|c|c|c|}
\hline $\begin{array}{c}\text { Young's } \\
\text { Modulus } \boldsymbol{E}\end{array}$ & $\begin{array}{c}\text { Yield strength } \\
\boldsymbol{R}_{\mathbf{p} \mathbf{0} .2}\end{array}$ & $\begin{array}{c}\text { Ultimate tensile } \\
\text { strength } \boldsymbol{R}_{\mathbf{m}}\end{array}$ & $\begin{array}{c}\text { Elongation at } \\
\text { break } \boldsymbol{\varepsilon}_{\mathbf{b}}\end{array}$ \\
\hline $208809 \mathrm{MPa}$ & $1915 \mathrm{MPa}$ & $2245 \mathrm{MPa}$ & $10.37 \%$ \\
\hline
\end{tabular}

From Table 1 it can be seen that in spite of the high ultimate tensile strength, the material's ductility is very high with an elongation at break $\varepsilon_{\mathrm{b}}$ of more than $10 \%$. The experimentally obtained values shown in the table are averaged from three tests. For further material characterization, strain-controlled fatigue tests were performed with various strain amplitudes between $0.33 \%$ and $4.65 \%$. The ratio of compressive to tensile strain was set at $R_{\varepsilon}=-1$ and testing was performed on a servo-hydraulic testing rig. Cracks were detected visually with a microscope and an approximate surface crack length of $0.5 \mathrm{~mm}$ was set as cracking criteria. The results are shown in Fig. 1.

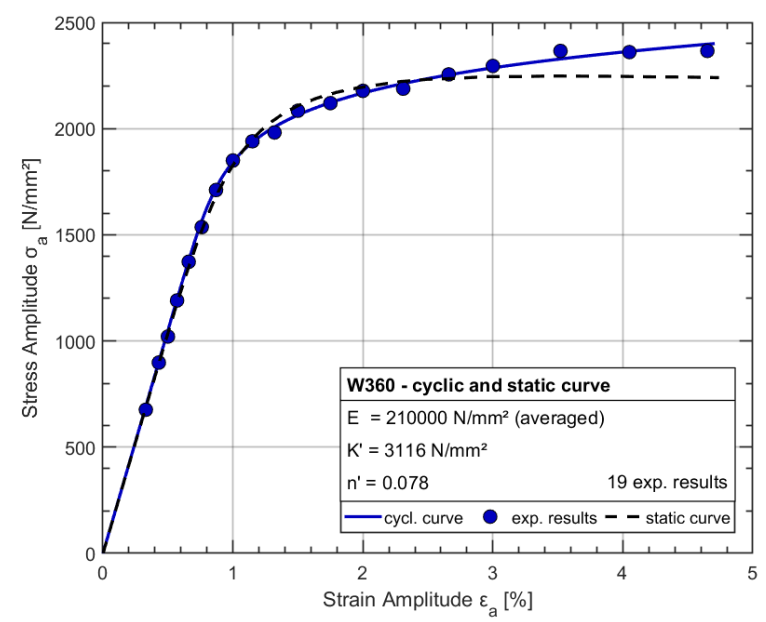

Fig. 1. Comparison of results from tensile testing (dashed curve) and cyclically stabilised curve fitted with Ramberg-Osgood relationship (full curve). 
From the recorded data of the fatigue tests, the strain amplitudes $\varepsilon_{\mathrm{a}}$ and the respective stress amplitudes $\sigma_{\mathrm{a}}$ were used to calculate the parameters $K^{\prime}$ and $n^{\prime}$ of the cyclically stabilised stress-strain curve with the Ramberg-Osgood equation, Eq. (1), which is shown in Fig. 1.

$$
\varepsilon_{\mathrm{a}}=\frac{\sigma_{\mathrm{a}}}{E}+\left(\frac{\sigma_{\mathrm{a}}}{K^{\prime}}\right)^{\left(\frac{1}{n^{\prime}}\right)}
$$

The parameters were fitted by linear regression of the logarithmic values of stress and plastic strain amplitudes while all plastic strain portions below $10^{-4}$ were ignored, according to [7]. In the Fig. 1, the measured stress-strain data are represented by dots and their fit with Eq. (1) is represented by the solid line. The dashed line represents the static curve from tensile testing, see Table 1. It can be seen that the material is showing cyclic hardening behaviour, where the stress amplitude grows higher than the ultimate tensile strength from the static curve.

\subsection{Material Modelling}

As the Autofrettage process takes place before the components are subjected to operational load conditions, for its simulation, the initial loading curve and the initial unloading curve of the material have to be taken into account $[1,3,4,5,6,8]$. If only the material's static tensile initial loading curve is used, the magnitudes of the induced compressive residual stresses and therefore the crack initiation lives will be overestimated [1, 6]. To avoid that, the material behaviour for FEA simulation, was split into two branches. For Autofrettage pressure-build up, the initial loading curve was discretised and the stress-strain points on the curve were used as initial loading curve with the kinematic hardening Besseling material model [9]. For pressure-unloading simulation, the cyclically stabilised curve from Fig. 1 was approximated by using the same material model.

\subsection{Finite Element Model}

The finite-element model for simulation of the Autofrettage process was created as a sixteenth of the real, component-like specimen used in the project, Fig. 2.
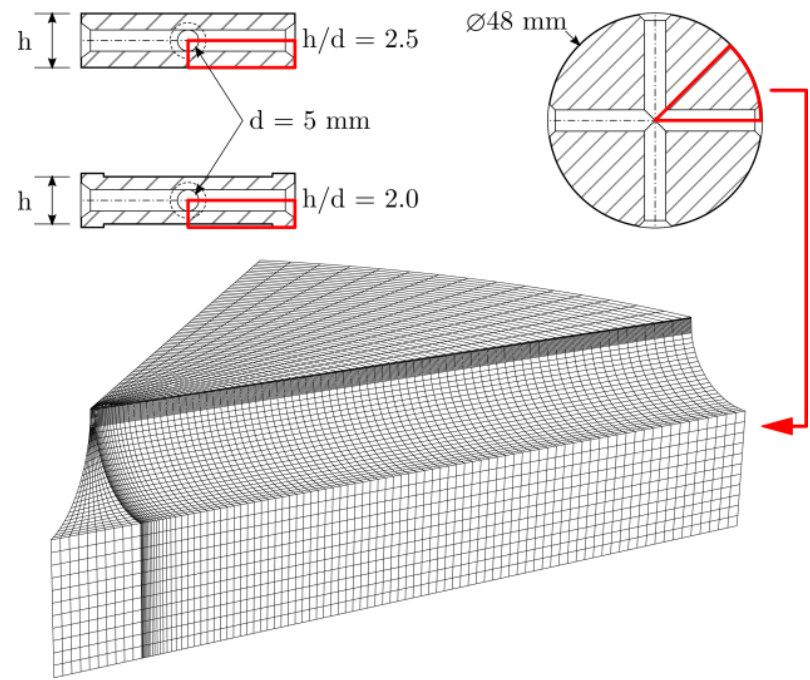

Fig. 2. Specimen geometry $h / d=2.5$ (upper left) and weakened geometry $h / d=2.0$ (left middle) with top view (upper right) and finite-element model for Autofrettage simulation. 
The component-like specimens were cylindrical with two 90 degree intersecting holes. The geometry was already used in previous projects $[1,2]$ and its bore intersection notches resemble those of common rails for Diesel applications. Two types of specimens were considered in the project: one specimen with a thickness $h$ to bore diameter $d$ ratio of $h / d=$ 2.5 and one, thinner, specimen with a ratio of $h / d=2$. The chamfers in the vicinity of the bore hole exits were neglected in the model, as crack initiation starts at the bore intersection notches [1, 2]. For choosing the best Autofrettage pressure, bursting pressures were approximated numerically with linear-elastic-ideal-plastic material behaviour by FEA with the method described in [1]. As maximum Autofrettage pressure approximately $92 \%$ of the bursting pressure was chosen. Table 2 shows all applied Autofrettage pressures for the specimens.

Table 2. Examined Autofrettage pressures for the two model geometries.

\begin{tabular}{|c|c|c|c|}
\hline Geometry & Ratio h/d & $\begin{array}{c}\text { Bursting } \\
\text { pressure in MPa }\end{array}$ & $\begin{array}{c}\text { Autofrettage pressures } \\
\boldsymbol{p}_{\text {af }} \text { in MPa }\end{array}$ \\
\hline Thick & 2.5 & 1855 & 1700,850 \\
\hline Thin & 2.0 & 1419 & $1300,1100,900,600,300$ \\
\hline
\end{tabular}

Previous research with the thicker specimen geometry has shown that cracks nucleate at the bore intersection notches and grow, along the bisector line between two intersecting bores $[1,2]$. The residual stress distributions along the line are shown in Fig. 3. Here it can be seen, that the residual stresses after maximum Autofrettage pressures show the same characteristic behaviour for both specimen types: Beginning from the bore intersection notch, the residual stresses decrease even further with greater depth into the material. The greatest negative residual stress is reached in a depth of about $0.9 \mathrm{~mm}$ for the thicker model and at a depth of $0.6 \mathrm{~mm}$ for the thinner model. For lower Autofrettage pressures, the minimum of the residual stress is located at the notch root and not in the depth of the bulk material.
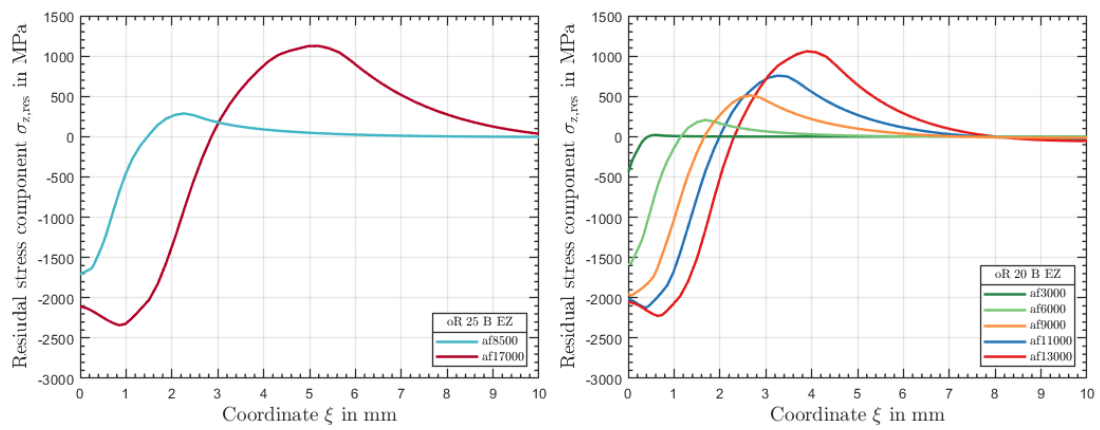

Fig. 3. Residual stress distributions along bisector for different Autofrettage pressures for the thick specimens (left) and the thinner specimens (right).

\section{Fatigue Life Calculations}

For non-autofrettaged specimens, the fatigue life-span is dominated by crack initiation life. With rising Autofrettage pressure, the influence of crack propagation life on the specimen's fatigue life increases drastically and even crack arrest can occur $[1,2,3,4,5,6]$, which leads to very high endurance limits, compared to non-autofrettaged specimens. 


\subsection{Crack Initiation Life}

Crack initiation life was calculated by a local strain approach with the damage parameter $P_{\mathrm{RAM}}$ as described in $[7,10,11,12]$ and first introduced by Bergmann [13], which is the damage parameter $P_{\mathrm{SWT}}$ with a consideration of mean stress sensitivity $M_{\sigma}$, see Eq. (2).

$$
P_{\mathrm{RAM}}=\sqrt{\left(\sigma_{\mathrm{a}}+k \cdot \sigma_{\mathrm{m}}\right) \varepsilon_{\mathrm{a}} E}
$$

In Eq. (2), $\sigma_{\mathrm{a}}$ represents the local stress amplitude, $\sigma_{\mathrm{m}}$ the local mean stress, $\varepsilon_{\mathrm{a}}$ the local strain amplitude and $k\left(M_{\sigma}\right)$ is the mean stress sensitivity factor, calculated with the mean stress sensitivity $M_{\sigma}$ as described in $[7,12]$. To calculate the values of the damage parameter $P_{\text {RAM }}$ for every of the tested fatigue specimens, Eq. (2) was used. Linear regression and an endurance limit of $N=10^{5}$ was then used to generate a damage parameter vs. cycles to failure curve.

\subsection{Crack Propagation Behaviour}

To identify the crack propagation behaviour, a linear elastic fracture mechanics approach was used, which is described in $[2,3]$. To estimate if a crack is prone to arrest, a linear elastic fracture mechanics approach utilising the range of the stress intensity factor $\Delta K$ was applied, see Eq. (3).

$$
\Delta K=K_{\max }-\max \left(K_{\min }, 0\right)
$$

Where the values of $K_{\max }$ and $K_{\min }$ are sums of the stress intensity factors due to maximum and minimum pressures on the bore surfaces, on the crack edges as well as the stress intensity factors due to the residual stress distribution along the bisectors. To calculate the stress intensity factors, a weight function developed for the specimen geometry and described in [3] was used. A threshold of $\Delta K_{\mathrm{th}}=163.4 \mathrm{MPa} \sqrt{\mathrm{mm}}$, obtained from own experimental data with CT-specimens at a stress ratio of $R=0$, was used. In Fig. 4, the $\Delta K$ ranges for different loading pressures, combined with the residual stress results from FEA for two thicker specimens $h / d=2.5$ with maximum Autofrettage pressure $p_{\text {af }}=1700 \mathrm{MPa}$ and Autofrettage pressure $p_{\mathrm{af}}=850 \mathrm{MPa}$ are shown.
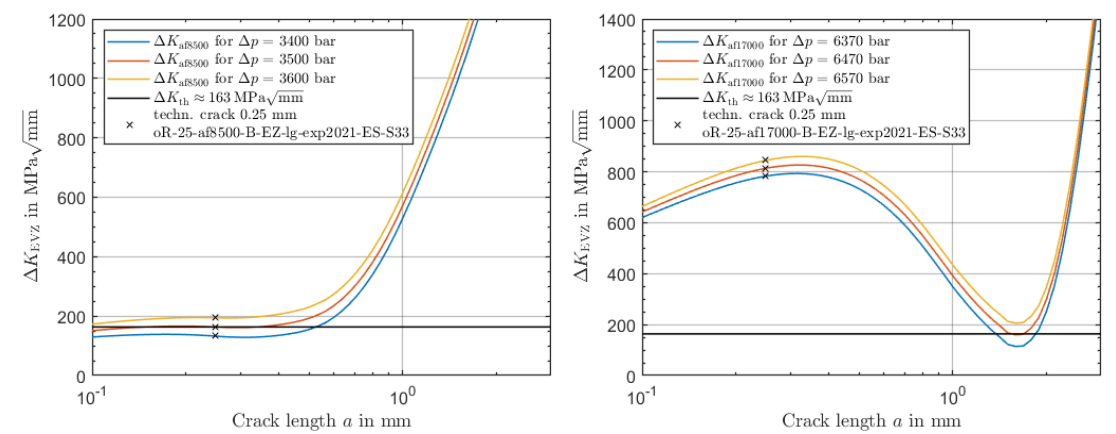

Fig. 4. $\Delta K$ ranges for different loading pressures for different residual stress distributions for two thick specimens $h / d=2.5$ from an Autofrettage pressure of $850 \mathrm{MPa}$ (left) and $1700 \mathrm{MPa}$ (right).

On the left hand side in Fig. 7, it can be seen that the range of the stress intensity factors never drops below the threshold value after the initial crack length of $0.25 \mathrm{~mm}$ which is marked by x symbols. For the fully autofrettaged specimen, shown on the right hand side, 
the stress intensity factor range drops below the threshold for load ranges of $\Delta p \leq 647 \mathrm{MPa}$. The assumption in Eq. (3) is that a crack grows under the influence of a stress intensity factor greater than zero.

\subsection{Crack Propagation Life}

Using the same weight function from [2,3], the crack propagation life was calculated for all specimen geometries and Autofrettage pressures. Calculation was based on the yield strip model as described in [3] where the crack flanks are subjected to the loading pressure range $\Delta p=p_{\max }-p_{\min }$. The maximum pressures were varied while the minimum pressure was set to be $p_{\text {min }}=5 \mathrm{MPa}$. Crack lengths from $a_{0}=0.25 \mathrm{~mm}$ to a final crack length of $a_{\text {end }}=$ $3.0 \mathrm{~mm}$ were considered. The residual stress distributions for each specimen geometry along the bisector, as shown in Fig. 6, were used.

\section{Comparison to experimental Results}

Component-like specimens, shown in Fig. 5, were manufactured out of W360 steel and tested at the MFPA in Weimar. For the thicker specimens $h / d=2.5$, testing was performed with non-autofrettaged specimens (naf) and specimens subjected to Autofrettage pressures of $p_{\text {af }}=850 \mathrm{MPa}=8500 \mathrm{bar}$ as well fully autofrettaged specimens with a pressure of $p_{\text {af }}=$ $1700 \mathrm{MPa}=17000$ bar. The specimens were loaded with pulsating inner pressure until failure at a load ratio of $R_{p} \approx 0$ with the minimum pressure set to $p_{\min }=5 \mathrm{MPa}$, with leakage being the failure criterion. The component-like specimens $\mathrm{h} / \mathrm{d}=2$, were tested after Autofrettage treatments with varying pressures $p_{\mathrm{af}}=[1300,1100,900,600,300] \mathrm{MPa}$. For the thinner specimens, testing was performed with a pressure-raising technique, where the loading pressure was increased, once a specimen had withstood $N=10^{6}$ cycles without failure. The experimentally obtained results for the thicker specimens are shown in Fig. 5.

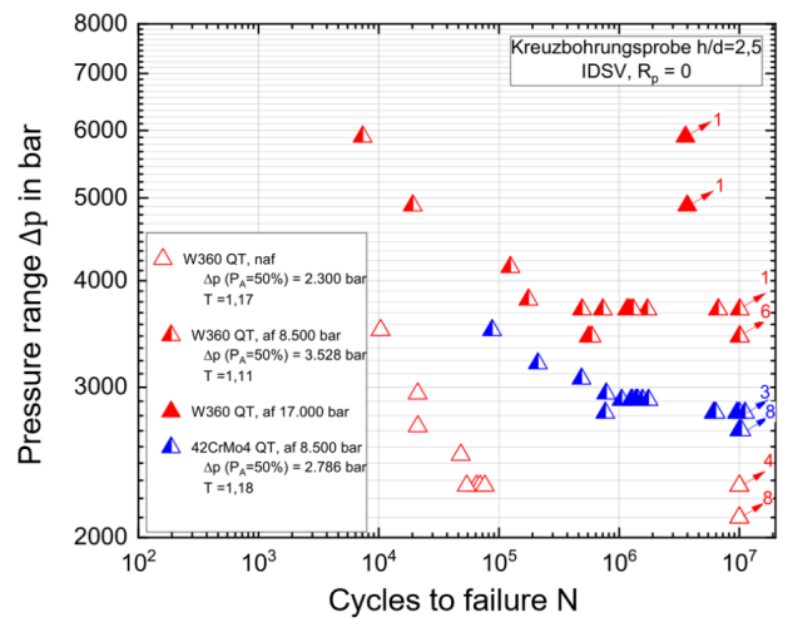

Fig. 5. Experimental results from pulsating inner-pressure testing at MFPA in Weimar for component-like specimens from W360 (red) and 42CrMo4 (blue) after treatment with different Autofrettage pressures.

Red symbols represent data for the W360 material. Non-filled symbols are nonautofrettaged specimens, half-filled symbols represent specimens which were autofrettaged at $p_{\mathrm{af}}=850 \mathrm{MPa}$ and fully-coloured symbols represent fully-autofrettaged specimens with $p_{\text {af }}=1700 \mathrm{MPa}$. Run-outs are marked with arrows, the small numbers at arrows denote the 
amount of run-out specimens. Blue symbols represent fully-autofrettaged specimens made of the quenched and tempered steel 42CrMo4, as investigated in $[1,2,3]$. The endurance limit for non-autofrettaged 42CrMo4 specimens (not shown in the figure) was $132.9 \mathrm{MPa}$, see [3].

As the endurance limit is of great practical interest. In Fig. 6 and Fig. 7, the endurable pressure ranges from experiments, shown with green dots, are compared to the calculated endurable pressure ranges for crack initiation (x-symbols) and crack propagation (circles).

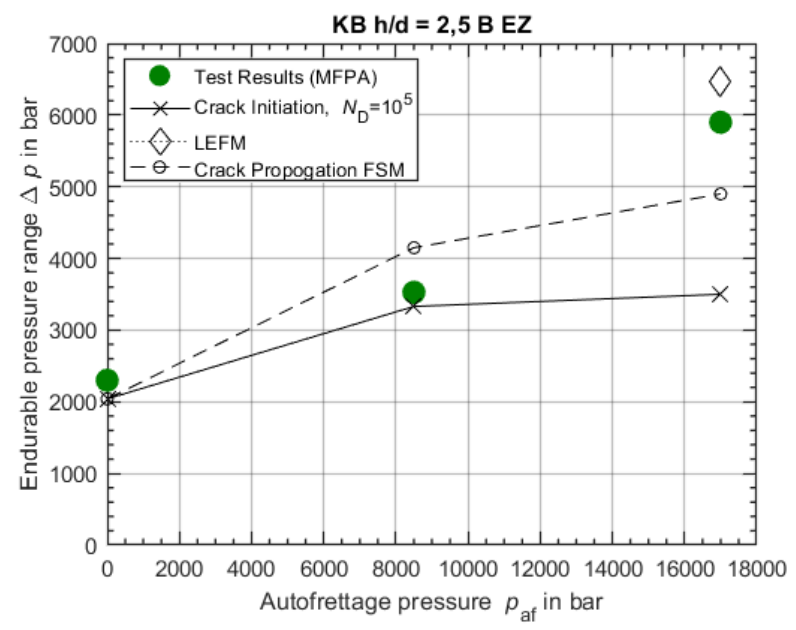

Fig. 6. Comparison of experimentally obtained endurance limits and calculated endurance limits for crack initiation, crack arrest and crack propagation for thicker specimens.

In the figures, the increasing influence from crack propagation on the endurance limit correlating with the increase of the Autofrettage pressure can be seen. The increase of the endurable pressure range for crack initiation is very low in comparison.

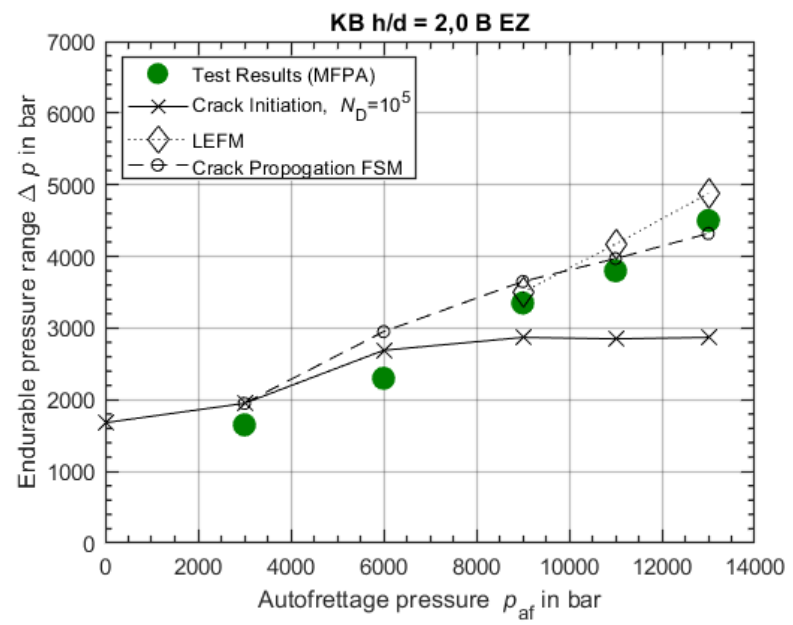

Fig. 7. Comparison of experimentally obtained endurance limits and calculated endurance limits for crack initiation, crack arrest and crack propagation for thinner specimens. 


\section{Conclusion}

In this report, plenty of fundamental experimental data was obtained for the investigation of the applicability of an ultra high strength steel for pressure loaded specimens. The increase of the endurance limit for autofrettaged specimens of a factor of 2 could even be surpassed with component-like specimens made of the investigated steel W360. For non-autofrettaged specimens, the endurance limits have to be investigated using calculation concepts for crack initiation. The calculated results for crack initiation lives overestimate the experimentally obtained results. For higher Autofrettage pressures, an appropriate description of the material behaviour during the Autofrettage process and, consequently the resulting residual stress field is crucial for the following fatigue life calculations. Here, different modelling approaches are possible which easily can over- or underestimate the resulting residual stresses. Using the linear-elastic fracture mechanics approach for investigation of possible crack arrest behaviour delivered slightly higher endurance limits than the experiments. The yield strip model approach used, also delivered slightly too high results describing the crack propagation behaviour and the endurance limits of the autofrettaged specimens. Still, the introduced residual stress distribution and the calculated crack initiation lives highly affect the results for crack propagation.

Acknowledgements: This work is part of an AiF/iGF project under the funding code $19790 \mathrm{~N}$ and is supported by the Federal Ministry for Economic Affairs and Energy on the basis of a decision by the German Bundestag.

\section{References}

1. R. Thumser, Simulation des Rissfortschritts in autofrettierten und nicht autofrettierten Bohrungsverschneidungen auf der Grundlage der linear-elastischen Bruchmechanik, Dissertation (2009)

2. M. Vormwald, T. Schlitzer, D. Panic, and H. T. Beier, Int. J. o F., 113, 428 (2018)

3. H. Th. Beier, J. W. Bergmann, A. Diemar, A. Kleemann, S. Kleemann, D. Panic, T. Richter, T. Schlitzer, M. Vormwald, Einfluss der Betriebstemperatur auf die Dauerfestigkeit autofrettierter Bauteile und einsatzgehärteter Bauteil von Dieseleinspritzsystemen: Vorhaben Nr. 1160. Forschungsvereinigung Verbrennungskraftmaschinen e.V. (FVV), Frankfurt, 2017.

4. E. Herz, O. Hertel, M. Vormwald, E. Fract. Mech., 78(3), 559 (2011)

5. E. Herz, R. Thumser, J.W. Bergmann, M. Vormwald, E. Fract. Mech., 73(1), 3 (2006)

6. R. Thumser, J.W. Bergmann, M. Vormwald, Int. J. Pres. Ves. Pip., 79(2), 113 (2002)

7. M. Fiedler, M. Wächter, I. Varfolomeev, M. Vormwald, and A. Esderts, FKM-

Richtlinie: Rechnerischer Festigkeitsnachweis unter expliziter Erfassung nichtlinearen Werkstoffverformungsverhaltens Für Bauteile aus Stahl, Stahlguss und Aluminiumknetlegierungen, FKM-Richtlinie. VDMA-Verlag GmbH, Frankfurt, 2019.

8. P. C. T. Chen, J. of Pres. Ves. Techn., 108, 108 (1986)

9. J.F. Besseling, ASME J. o. Appl. Mech., 25, 529 (1958)

10. M. Fiedler, M. Vormwald, Matec Web of Conferences 165, 10014 (2018)

11. M. Fiedler, M. Vormwald, Theo. and Appl. Fract. Mech., 83, 31 (2016)

12. M. Fiedler, M. Vormwald, Mat. und Werkstofftech., 47(10), 887 (2016)

13. J. W. Bergmann, Zur Betriebsfestigkeitsbemessung gekerbter Bauteile auf der Grundlage der örtlichen Beanspruchungen, TH Darmstadt, Germany, (1983) 